\title{
EVIDENCE FOR MOTILE SUCTION TRAPS IN UTRICULARIA WESTONII FROM UTRICULARIA SUBGENUS POLYPOMPHOLYX
}

\author{
SimON PopPINGA • Plant Biomechanics Group • Botanic Garden • University of Freiburg • Freiburg \\ im Breisgau • Germany • simon.poppinga@biologie.uni-freiburg.de \\ MARCo PeZzotTa • San Salvo $(\mathrm{CH}) \cdot$ Italy • marco.pezzotta@hotmail.it \\ ANDREAS FleISCHMANN • Botanische Staatssammlung München • Munich•Germany•fleischmann@ \\ bio.lmu.de
}

Abstract: Here we report that traps of Utricularia westonii from Utricularia sect. Tridentaria are working with a very effective suction mechanism, which was revealed and recorded during feeding experiments with cultivated specimen.

The bladderworts (Utricularia spp., Lentibulariaceae) comprise more than 240 species with several life-forms (Fleischmann 2015). It is generally believed that they capture their prey with leaves that are modified into suction traps, commonly termed "bladders", which are the fastest trapping devices among carnivorous plants (Lloyd 1942). Suction is rendered possible by a complex interplay of functional-morphological, physiological and mechanical prerequisites (reviewed by Poppinga et al. 2016). Water pumps shift water from the trap lumen to the exterior, thereby generating a sub-ambient pressure inside the traps. The trap walls are elastically deformable and thereby store elastic energy. Furthermore, the traps are closed watertight by a thin and flexible trapdoor, which can swiftly open and close after touch by prey to allow the traps to perform their suction strike.

There has been some debate recently whether traps of phylogenetically early branching terrestrial or affixed aquatic species from Utricularia subg. Polypompholyx meet the above criteria, i.e. if they possess motile suction traps, or if they work as non-motile eel traps similar to those of Genlisea (Fleischmann et al. 2012). Especially U. multifida (U. sect. Polypompholyx) has been investigated in this respect: although Lloyd (1942) reported that the traps are motile, later analyses by Reifenrath et al. (2006), finding that they possesses exceptionally thick trapdoors, and Westermeier et al. (2017), which were unable to record suction events in laboratory experiments, have led to speculations that they might be non-motile on the contrary. Płachno et al. (2019) attributed the traps of $U$. multifida and $U$. westonii ( $U$. sect. Tridentaria) to possess the structural prerequisites for suction, but could not definitively prove this trap functioning experimentally. Utricularia tenella (U. sect. Polypompholyx) has never been investigated in this respect. At least for $U$. westonii, which is endemic to Cape Le Grand National Park, southwestern Western Australia (Fig. $1 \mathrm{~A}, \mathrm{~B})$, the exact trap functional principle can be considered as revealed with this short communication.

Marco Pezzotta grew this species from November 2016 until March 2020 following a methodology proposed by Spence (2005). The seeds of this annual species, which grows during winter, were originally obtained from Allen Lowrie. The plants were cultivated outside for their whole life cycle in San Salvo $(\mathrm{CH})$, Italy, which is characterized by a Mediterranean climate with winter temperatures never below $0^{\circ} \mathrm{C}$. The sowing was carried out in late summer on a substrate consisting of peat and fine quartz sand in a ratio of 40/60 and with a superficial layer of sand only. The pots have been placed in a container, with a level of demineralized water slightly lower than the surface of the substrate. Then the pots have been covered with a transparent lid to avoid rain and to limit evaporation. During germination, which can take from a few weeks to a couple of months, direct sunlight illumination is not required. Once the seedlings had anchored to the substrate with their rhizoids, after 

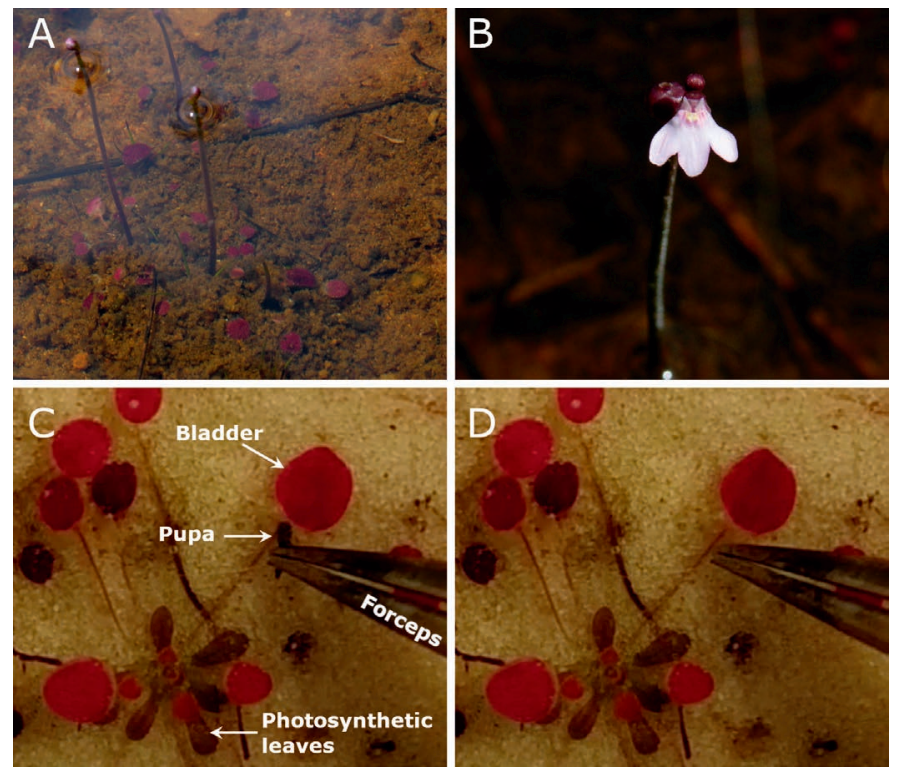

Figure 1: Utricularia westonii. A) Submerged plants in the Cape Le Grand National Park. B) Flower. C) Feeding of a cultivated plant with a dipteran pupa. The pupa is handled with forceps and brought to the entrance zone of the trap. D) The pupa has been sucked into the trap. The two frames C) and D) are from a movie, which can be seen on Marco Pezzotta's YouTube channel (FreakyPlants Marco Pezzotta), or be obtained from the authors upon request. The movie was recorded with $30 \mathrm{fps}$, the time duration between the two frames hence is $\sim 33 \mathrm{~ms}$. However, the real duration of suction is likely to be even faster. The movement of the lateral trap walls is not visible in this recording. Photos A, B by A. Fleischmann, C, D by M. Pezzotta.

reaching about 3-4 leaves, the water level was raised about 2-5 $\mathrm{cm}$ above the substrate in order to submerge the plants. The water in which the plants were grown contained crustaceans such as copepods and ostracods for allowing the plants to capture prey essential for growing and flowering. The flower scapes began to emerge in spring and, when possible, the plants were cross-pollinated. In all the other cases, plants were allowed to self-pollinate. Both procedures led to the production of fertile seeds.

Marco was able to film suction in his cultivated plants with a mobile phone camera (Xiaomi Redmi Note 5) (Fig. 1C,D). A video of the suction action can be seen on his YouTube channel (FreakyPlants Marco Pezzotta, https://www.youtube.com/watch?v=UOKThdl1JFg), or be obtained from the authors upon request. The video shows that suction is triggered during feeding with an immobile dipteran pupa (3.1 mm length on average, $\mathrm{n}=5$ ), which is handled with a pair of forceps. Indeed, this is a very elegant method of feeding prey to the traps ( $3.4 \mathrm{~mm}$ length on average, $\mathrm{n}=5$, without appendices). Marco regularly observed suction actions during the feeding procedures, so that the suction event presented in Figure 1C,D (and in the respective video) is not an exception. Indeed, $U$. westonii is described to possess trigger hairs on its trapdoor (Płachno et al. 2019), which are responsible for trap activation upon touch in bladderworts in general (Lloyd 1942). The swift displacement of the dipteran pupa between two frames of the recording (relating to a duration of $\sim 33 \mathrm{~ms}$ [milliseconds] according to $30 \mathrm{fps}$ recording speed) is indicative of a rapid suction action. However, we believe that the timescale is presumably even (much) 
smaller, as suction in Utricularia can be ultra-fast: about $9 \mathrm{~ms}$ were measured in aquatic $U$. australis by Poppinga et al. (2017). Due to the triangular shape of the U. westonii trap (as seen in transverse section) (Taylor 1989) and the orientation of the recording camera, the movement of the lateral trap walls is not visible. The trap motion can be resolved in full temporal resolution only with adequate high-speed camera setups and remains an interesting aspect for future approaches, e.g. for studying fluid dynamics.

Until now, we do not know which prey is being caught by species of Utricularia subg. Polypompholyx. Probably, the conspicuous trap shapes in combination with the terrestrial/affixed aquatic lifestyles represent adaptations to capture shelter-seeking crustaceans like small ostracods. We also do not know if these traps are capable of sucking spontaneously, i.e. without being triggered mechanically by prey. This autonomous behaviour is reported from many aquatic and non-aquatic species (Vincent et al. 2011; Westermeier et al. 2017) and helps these plants to accumulate digestible biomass like algae in their traps (Koller-Peroutka et al. 2015). In conclusion, many functional aspects remain unclear for these phylogenetically early branching species.

Acknowledgements: The authors acknowledge the efforts and constructive comments of the two anonymous reviewers.

\section{References}

Fleischmann, A. 2012. Monograph of the Genus Genlisea. Poole, UK: Redfern Natural History Productions.

Fleischmann, A. 2015. Taxonomic Utricularia news. Carnivorous Plant Newsletter 44: 13-16.

Koller-Peroutka, M., Lendl, T., Watzka, M., and Adlassnig, W. 2015. Capture of algae promotes growth and propagation in aquatic Utricularia. Annals of Botany 115: 227-236. (doi:10.1093/aob/mcu236) Lloyd, F.E. 1942. The Carnivorous Plants. Waltham, USA: Chronica Botanica.

Płachno, B.J., Świątek, P., Adamec, L., Carvalho, S., and Miranda, V.F.O. 2019. The trap architecture of Utricularia multifida and Utricularia westonii (subg. Polypompholyx). Frontiers in Plant Science 10: 336. (doi:10.3389/fpls.2019.00336)

Poppinga, S., Weißkopf, C., Westermeier, A.S., Masselter, T., and Speck, T. 2016. Fastest predators in the plant kingdom: functional morphology and biomechanics of suction traps found in the largest genus of carnivorous plants. AoB PLANTS 8: plv140. (doi:10.1093/aobpla/plv140)

Poppinga, S., Daber, L.E., Westermeier, A.S., Kruppert, S., Horstmann, M., Tollrian, R., and Speck, T. 2017. Biomechanical analysis of prey capture in the carnivorous Southern bladderwort (Utricularia australis). Scientific Reports 7: 1776. (doi:10.1038/s41598-017-01954-3)

Reifenrath, K., Theisen, I., Schnitzler, J., Porembski, S., and Barthlott, W. 2006. Trap architecture in carnivorous Utricularia (Lentibulariaceae). Flora 201: 597-605. (doi:10.1016/j.flora.2005.12.004)

Spence, S. 2005. Growing annual south western WA Utricularia species from seed. Victorian Carnivorous Plant Society Journal 78: 12-14.

Taylor, P. 1989. The Genus Utricularia: A Taxonomic Monograph. London, UK: Kew Bulletin, Additional Series, XIV.

Vincent, O., Roditchev, I., and Marmottant, P. 2011. Spontaneous firings of carnivorous aquatic Utricularia traps: temporal patterns and mechanical oscillations. PLoS ONE 6: e20205. (doi:10.1371/journal.pone.0020205)

Westermeier, A.S., Fleischmann, A., Müller, K., Schäferhoff, B., Rubach, C., Speck, T., and Poppinga, S. 2017. Trap diversity and character evolution in carnivorous bladderworts (Utricularia, Lentibulariaceae). Scientific Reports 7: 12052. (doi:10.1038/s41598-017-12324-4) 